\title{
Infection Control Pharmacist: A New Initiative Project in the Kingdom of Saudi Arabia
}

\author{
Yousef Ahmed Alomi*, (D) BSC. Pharm, \\ MSc. Clin Pharm, BCPS, BCNSP, DiBA, CDE, \\ Critical Care Clinical Pharmacists, TPN \\ Clinical Pharmacist, Freelancer Business \\ Planner, Content Editor and Data Analyst, \\ Riyadh, Saudi Arabia. \\ Anhar Mohammed Alyousef, Pharm D. \\ Innova health care company Riyadh, Saudi \\ Arabia.
}

\section{Correspondence:}

Dr. Yousef Ahmed Alomi, BSc. Pharm, MSc. Clin Pharm, BCPS, BCNSP, DiBA, CDE, Critical Care Clinical Pharmacists, TPN Clinical Pharmacist, Freelancer Business Planner, Content Editor and Data Analyst, Riyadh 11392, Riyadh, Saudi Arabia.

Phone no: +966504417712

E-mail: yalomi@gmail.com
Received: 23-08-2020;

Accepted: 10-11-2020.

Copyright: (c) the author(s),publisher and licensee Pharmacology, Toxicology and Biomedical Reports. This is an open-access article distributed under the terms of the Creative Commons Attribution NonCommercial License, which permits unrestricted non-commercial use, distribution, and reproduction in any medium, provided the original work is properly cited.

This is an open access article distributed under the terms of the Creative Commons AttributionNonCommercial-ShareAlike 4.0 License

Access this article online

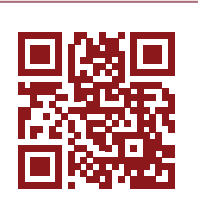

www.ptbreports.org

DOI:

10.5530/PTB.2021.7.8

\begin{abstract}
Objectives: To declare the Infection control pharmacist as new initiatives in the Kingdom of Saudi Arabia. Methods: It is a new initiative project drove by national and international Infection control regulations and guidelines. The projects are formulated from the global business model, pharmacy project guidelines and professional project management elements. The initial project followed the project management professionals, including the initial phase, the planning phase, the execution phase and the monitoring and controlling phase. Results: The vision, mission and goals of the Infection control pharmacist are explored. The services had various benefits, including clinical and economical, on patients, as illustrated in the review. The continuous of the project revised by the risk management model description. Moreover, the monitoring and controlling of the services as declared. The transition to operation project through closing project stage explored in the analysis. Conclusion: The Infection control pharmacist is a new initiative and part of the clinical pharmacy specialties and pharmacy infection control services. The Infection control pharmacist meet the demand of pharmacy infection control, prevent infection control related problems and contribute during epidemic or pandemic and medical disaster; it is highly suggested to implement in Saudi Arabia
\end{abstract}

Key words: Infection control, Pharmacist, Pharmacy, Services, Initiative, Saudi Arabia.

\section{INTRODUCTION}

Over the past years, several epidemic or pandemic and public health emergency had occurred. From Acute Respiratory Syndrome (SARS), influenza A (H1N1), Middle East respiratory syndrome coronavirus (MERS-CoV), Zika virus-related disease and the Coronavirus Disease 2019 (COVID-19) $^{1,2}$ In each situation, essential infection control tools had been done to prevent the infection spread throughout several countries. ${ }^{3-5}$ The infection control starting from use necessary infection control measures of hand wishing techniques, using sanitizer or chemical disinfectant and isolation of infected cases, or isolated of cities form to enter and outer from it $^{3-5}$ Besides, several studies showed resistance bugs locally and overall the world, ${ }^{6-10}$ and high consumption of broad spectrum of antibiotics and increased economic burden at emergency, inpatient ward, critical care and ambulatory care services. ${ }^{11-16}$ Moreover, the pharmacy services consisted of $\mathrm{m}$ preparation, distribution and dispensing parenteral or ophthalmic medications. Those pharmacy units need bright places and preparation of sterile products. As a result, the infection control tools for staff, equivalent, places, furniture required for all pharmacy services units to keep clean and without infected preparation. However, various reports showed there were some contaminated preparation lead to infected patients or death. ${ }^{17,18}$ Other studies showed knowledge and practice were poor adherence to infection control. Healthcare professionals, including physicians, dentists, or nurses and student healthcare, while full-time pharmacists have not existed until now. ${ }^{19-22}$ The clinical pharmacist specialized in infection control was suggested as one specialized clinical pharmacist in the pharmacy strategic plan with updated vision 2030 as an infection control pharmacist. $^{23}$ The American Society of Heath system pharmacist stated the pharmacist's role in the Antimicrobial Stewardship and infection control performances as combined in one specialty. ${ }^{24}$ There are various publications about general infection control. ${ }^{3-5,25-28}$ However, very few studies existed worldwide about pharmacy infection control. ${ }^{24,29}$ Based on their knowledge, they are not familiar with any investigations about infection control pharmacists locally or Gulf or Middle East countries and all the world about infection control pharmacists. The aim of this project review to declare the infection control pharmacist as new initiatives project in the kingdom of Saudi Arabia.

\section{Method of the project}

It is a new initiative project drove by international Infection control institutions programs. The task force team of Infection control pharmacist charity from the author's expertise in the pharmacy administration and infectious diseases and infection control healthcare professionals. The committee unitized international infection control for healthcare professionals, including a pharmacist. Besides and international litterateur of infection control pharmacy. It was written by utilizing the global business model, pharmacy project guidelines and professional project management elements of a new project. ${ }^{30-33}$ The Infection control pharmacist is based on the type of infection control and pharmacy units need 
infection control system, job description of Infection control pharmacist and Infection control pharmacist activities. The project followed project management professionals and consisted of several parts, including the initial phase, the planning phase, the execution phase and the monitoring and controlling phase.

\section{Initial phase}

\section{Assessment needs}

Pharmacists and pharmacy technicians prepare multiple medications at all pharmacy units, including the intravenous administration, inpatient and outpatient pharmacies. Besides, compounding of extemporaneous preparations. All those preparations as parenteral or oral route need to be without any bugs contamination. That preparation of medications requires an infection control tool to test random samples from that preparation to check and assure without bugs contamination, incredibly sterile Intravenous or ophthalmic preparation and oral extemporaneous oral or topical preparation. The accident contamination of needle stick during medications preparation need particular guidelines and monitoring the accident cases. The sanitizer and chemical disinfectant of the shelf, floor, furniture of pharmacy departments need an approach for usage. Moreover, the active surveillance of contamination bugs of pharmaceutical preparation, or infected staff pharmacists, return medications from healthcare departments. All previous reasons required unique trained pharmacist or specialized clinical pharmacists on pharmacy infection control to implement and implement all last performance and activities.

\section{SWOT analysis}

SWOT analysis is considered one of the standard tools for each current project was the analysis of Infection control pharmacists. The SWOT analysis is idenfying strength, weakness, opportunities and threats. The project's strengths are setup up the Infection control pharmacist, providing appropriate pharmacy infection control, preventing sanitizer and chemical disinfectant mistakes and building infection control and sanitation culture. In contrast, the weak points are the limited number of pharmacy staff, including clinical pharmacists. The opportunities point to high demand for infection control pharmacists during epidemic or pandemic and public health emergency from the program implementation, the availability of approved infection control education and training programs. The threat points are if the pharmacy strategic plan does not exist in pharmacy infection control and if the administration planner not available.

\section{Market Analysis}

The majority of the healthcare organizations had pharmaceutical care services and consisted of inpatient pharmacy, outpatient pharmacy, intravenous admixture services, drug information center and clinical pharmacy services. Besides, the pharmacy's total quality management and medication safety officers. However, the infection control pharmacist not existed at all healthcare institutions in Saudi Arabia. Most hospitals or community pharmacists had implemented general infection control as one unit of other healthcare departments. However, infection control for pharmacy in such detail not existed in practice. Some hospitals had clinical pharmacists specialized in infectious diseases to take care of some infection control pharmacists' jobs like antimicrobial resistance, while sanitizer or chemical disinfectant for all sections of pharmacy units not available. The pharmacy unit implemented an intravenous admixture with some monitoring parameters of infection control in the testing bugs of laminar flow hood, the equipment used for sterile parental medications. Preparation made guidelines for parenteral dilution and administration of the medicines special for them. The procedures consisted of medications, drug strength, rate of administration and stability of intravenous infusions. This pharmacy practice situation looks like other Gulf and Middle East countries while nothing available in the local and even the international market.

\section{Planning phase}

\section{Scope of the project}

The project covers an Infection control pharmacist. That includes common types of Infection control pharmacist practice, the pharmacy infection control program and the administration of Infection control in the hospital and community pharmacy. Moreover, the job description of Infection control pharmacists.

\section{Vision, Missions, Goals}

The project's vision is to reach the best Infection control pharmacist job, while the message to provide the appropriate Infection control pharmacist performance and activities to the pharmacy organizations and populations. The goals of the project to fix the Infection control pharmacist job, to inhibit any compounding mistakes related to pharmacy infection control, to reduce the workload for pharmacy staff on pandemic and emergency public Heath, to implement the pharmacy infection control during regular days and mass gatherings pharmaceutical care Hajj and Omra and to avoid the additional unnecessary and additional cost on the pharmacy and healthcare system as the impact of Infection control pharmacist

\section{Project description}

The following policies were put in place for every pharmacy staff and other health care individuals:

$\checkmark$ The Pharmacy Infection control committee should be formulated at healthcare institutions

$\checkmark$ The Pharmacy infectious control committee should consist of an infection control pharmacist as head of the committee and other members including IV pharmacist, the inpatient pharmacist, ambulatory care pharmacist and pharmacy technician and infection control representative,

$\checkmark$ The committee revises the standardized Infection control pharmacist and pharmacy services and updates at least annually.

$\checkmark$ The Infection control pharmacist education and training sessions should be conducted by the committee to all healthcare providers, including physicians and nurses, with pharmacy staff.

$\checkmark$ The Infection control pharmacist distributed to healthcare sectors at the organization

$\checkmark$ The Infection control pharmacist implement the infection control at all pharmacy services based on national and international infection control guidelines and regulations

$\checkmark$ The Infection control pharmacist prescribes the sanitizer and disinfectant for the pharmacy environment, units and staff.

$\checkmark$ The Infection control prescription should be sent to all pharmacy sections, clinical compounding pharmacist for preparation if necessary and IV pharmacist.

$\checkmark$ The Infection control pharmacist makes daily and periodically round of pharmacy infection control for active surveillance to all pharmacy staff, pharmaceutical services and all IV medications in the hospital wards.

$\checkmark$ The Infection control pharmacy committee should measure the clinical outcome of the Infection control pharmacist

$\checkmark$ The Infection control pharmacy committee should measure the economic outcome of the Infection control pharmacist

$\checkmark$ The Infection control pharmacist should document any preparation non-adherence to the standardized infection control 


\section{Plan cost management}

Every current new project Infection control pharmacist, the management team must set out the financial budget. This includes the cost of Infection control pharmacist educational courses pharmacy staff and healthcare professionals, the management team meeting's expense and the cost of updated pharmacy infectious control references. The budget must be supervision over a while until the project is finished and switch to the operating system.

\section{Executing phase}

\section{Management team}

Project management professionals had multiple steps. One of the essential steps was the executing phase, a team lead the project from the beginning until becoming one of the healthcare organization's operating systems. The team consisted of several members, infectious disease clinical pharmacists, distributive pharmacists, infection control medical physicians and nurses, pharmacy technician experts in the infection control, pharmacy quality management and medication safety officer representing. The team should implement and follow up on the new services Infection control pharmacist with regular updating of the job description. Moreover, the team need to educate and train the pharmacy staff and healthcare staff about the new services Infection control pharmacist and measure the project's clinical and economic outcome.

\section{Education and training}

The new project requires infection control pharmacists need education and training for concerned people. This project needs education and training for pharmacy staff, including clinical pharmacists, pediatrics pharmacists and pharmacy technicians. The healthcare professionals, including infection control physicians and nurses, need another special education and infection control pharmacists training. Moreover, orientation for the team management required about the project Infection control pharmacist for all healthcare professionals. The orientation emphasis any new staff healthcare providers joined the healthcare institutions. The Infection control pharmacist needs special education and training about infection control and epidemiology.

\section{Project total quality management}

There are various methods used for total quantity management required for the project infection control pharmacist, while the implementation phase reflects the impact. The balance scored cards were among them. ${ }^{34}$ The monitoring tools consisted of the customer, finance, internal process, education and innovation. For instance; The assessment of healthcare services was an example of an internal process type. The infection control pharmacist project's clinical outcome reflects the education and competency of pediatrics clinical pharmacists, pharmacists, pharmacy technicians were as an example of the education style. The measuring the cost avoidance of the Infection control pharmacist is an example of financial type. The fourth type was the customer types measuring the patient's satisfaction with healthcare providers, including pharmacists and pharmacy technicians, Infection control pharmacist satisfaction in Saudi Arabia.

\section{Risk Management}

There are multiple considered risks, including schedule risks, scope risks, budget risks, personal risks, technical risks and quality risks. ${ }^{35,36}$ The project is mostly exposed to personnel, budget, technical and quality risks with the current new project Infection control pharmacists. The project adequately suffered from personal threats with not trained pharmacy staff or sufficient pharmacists and pharmacy technicians. The financial budget risk; not covered the Infection control pharmacist education and training courses for all pharmacy staff and healthcare professionals. There is another technical risk that might be exposed. The technical included limited electronic recourses of pharmacy infection control or not existed the active surveillance computer system in pharmacy practice. The project maybe is exposed to quality risks with not implemented safety tools of infection control pharmacists; or nontrained personnel. Moreover, the scope risk may be exposed to Infection control pharmacists and various activities might conflict with infectious disease pharmacists.

\section{Closing of the project}

The infection control pharmacist at all healthcare services, either governmental and private sectors, is required. To prevent infection in the pharmaceutical material, equipment, personnel-related issues and avoid infection control-related mistakes, it will lead to morbidity and mortality and avoid an economic burden on pharmacy and healthcare system, including the hospitals and community pharmacies services Saudi Arabia. The project should continue at the Infection control pharmacist Intravenous at each hospital and community pharmacy unit and keep supervision through related committees. The Infection control pharmacist education and training should be implemented accordingly. Infection control pharmacist Performances and activities should Update regularly and expand the quantity and quality of the activities are recommended in the future. The annual celebration of all Infection control pharmacists, including clinical pharmacists, pharmacist and pharmacy technician, is highly recommended in Saudi Arabia

\section{ACKNOWLEDGEMENT}

None.

\section{CONFLICT OF INTEREST}

None.

Funding

None

Consent for Publications

Non applicable

\section{Ethical Approval}

This research is exempted from research and ethical committee or an institutional review board (IRB) approval.

https://www.hhs.gov/ohrp/regulations-and-policy/decisioncharts-2018/index.html

\section{ABBREVIATIONS}

MOH: Ministry of Health; KSA: Kingdom of Saudi Arabia; ASHP: American Society of Health-System Pharmacists; SWOT: Strengths, Weaknesses, Opportunities and Threats; IV: Intravenous; BSC: Balance Scored Cards; SARS: Acute Respiratory Syndrome; H1N1: influenza A; MERS-CoV: Middle East respiratory syndrome coronavirus; COVID-19: Coronavirus Disease 2019.

\section{ORCID ID}

Yousef Ahmed Alomi (iD https://orcid.org/0000-0003-1381-628X

\section{REFERENCES} 1. Alhazzani W, Møller MH, Arabi YM, Loeb M, Gong MN, Fan E, et al. Surviving
Sepsis Campaign: guidelines on the management of critically ill adults with
Coronavirus Disease 2019 (COVID-19). Intensive Care Med. 2020;46(5):854-87.
2. Shehab N, Brown MN, Kallen AJ, Perz JF. Public Health and Patient Safety Lessons Learned. J Patient Saf. 2015;1-10. Available from: www. 
journalpatientsafety.com

3. WHO. Practical Guidelines for Infection Control in Health Care Facilities. World Heal Organ. 2004;41:110. Available from: http://www.wpro.who.int/ publications/docs/practical_guidelines_infection_control.pdf

4. Rutala WA, Weber DJ, Weinstein RA, Pearson ML. Guideline for Disinfection and Sterilization in Healthcare Facilities, Miscellaneous Inactivating Agents. CDC Website. 2019. 2008. Available from: http://www.cdc.gov/hicpac/ Disinfection_Sterilization/10_0MiscAgents.html

5. AlKnawy B, Khoja T, Balkhy H, Pittet D. GCC Infection control manual. 2013;1 324.

6. Kaki R, Elligsen M, Walker S, Simor A, Palmay L, Daneman N. Impact of antimicrobial stewardship in critical care: A systematic review. J Antimicrob Chemother. 2011;66(6):1223-30.

7. Aly $\mathrm{M}, \mathrm{Balkhy} \mathrm{HH}$. The prevalence of antimicrobial resistance in clinical isolates from Gulf Corporation Council countries. Antimicrob Resist Infect Control. 2012;1(25):1-5.

8. AlYousef SA. Surveillance of antibiotic-resistant bacteria in King Khalid hospital, Hafr Al-Batin, Saudi Arabia, during 2013. Jundishapur J Microbiol. 2016;9(9).

9. Lakshmana GK, Marie MAM, Al-SheikhYA, John J, Gopalkrishnan S, Chikkabidare Shashidhar $\mathrm{P}$, et al. A 6-year surveillance of antimicrobial resistance patterns of Acinetobacter baumannii bacteremia isolates from a tertiary care hospital in Saudi Arabia during 2005-2010. Libyan J Med. 2014;9(1):24039.

10. The European Centre for Disease Prevention and Control. Antimicrobial resistance surveillance in Europe 2015. Annual Report of the European Antimicrobial Resistance Surveillance Network (EARS-Net). European Centre for Disease Prevention and Control. 2015;1-120.

11. Abdulhak AAB, Altannir MA, Almansor MA, Almohaya MS, Onazi AS, Mare MA et al. Non prescribed sale of antibiotics in Riyadh Saudi Arabia: A crosssectional study. BMC Public Health. 2011:11(1):538. Available from: http://www. biomedcentral.com/1471-2458/11/538

12. Alnemri AR, Almaghrabi $\mathrm{RH}$, Alonazi N, Alfrayh AR. Misuse of antibiotics: $A$ systemic review of Saudi published studies. Curr Pediatr Res. 2016;20(1-2):16973.

13. Almasoudi $A H$, Alomi YA, Alghamdi GA. Antimicrobial Drug Consumption in Ambulatory Care Settings, Tabuk Region, Saudi Arabia. Pharmacol Toxicol Biomed Reports. 2019;5(3):97-101.

14. Almasoudi AH, Alomi YA, Alghamdi GA, Alshahrani RS. Analysis of Antimicrobial Medications Consumption in Inpatient Units at North West (Tabuk) Region Hospitals, Saudi Arabia. Pharmacol Toxicol Biomed Reports. 2019;5(3):130-4.

15. Alomi YA, Almasoudi AH, Alghamdi GA, Abboud NA. Antimicrobial Drug Consumption in Emergency Services at North West (Tabuk) Region Hospitals, Saudi Arabia. Pharmacol Toxicol Biomed Reports. 2019;5(3):108-12.

16. Alomi YA, Almasoudi AH, Alghamdi GA, Ali AS. Analysis of Antimicrobial Medication Consumption in Intensive Care Unit, North West (Tabuk) Region Hospitals, Saudi Arabia. Pharmacol Toxicol Biomed Reports. 2019;5(3):119-23.

17. Staes C, Jacobs J, Mayer J, Allen J. Description of outbreaks of health-careassociated infections related to compounding pharmacies, 2000-12. Am J Heal Pharm. 2013;70(15):1301-12.

18. Birkhead G, Hamilton TE, Kossover R, Perz J, Gangadharan D, Iskander J. CDC grand rounds: Preventing unsafe injection practices in the U.S. Health-care system. Morb Mortal Wkly Rep. 2013;62(21):423-5.

19. Qudeimat MA, Farrah RY, Owais Al. Infection control knowledge and practices among dentists and dental nurses at a Jordanian university teaching center. Am
J Infect Control. 2006;34(4):218-22.

20. Adegboye MB, Zakari S, Ahmed BA, Olufemi GH. Knowledge, awareness and practice of infection control by health care workers in intensive care units of a tertiary hospital in Nigeria. Afr Health Sci. 2018;18(1):72-8

21. Peres $D$, Severo M, Ferreira MA. Knowledge, source of information and perception of Portuguese medical students and junior doctors of infection control precautions. Am J Infect Control. 2016;44(12):1723-5.

22. Khubrani A, Albesher M, Alkahtani A, Alamri F, Alshamrani M, Masuadi E. Knowledge and information sources on standard precautions and infection control of health sciences students at King Saud bin Abdulaziz University for Health Sciences, Saudi Arabia, Riyadh. J Infect Public Health. 2018;11(4):546-9.

23. AlomiYA Alghamdi SJ, Alattyh RA, Elshenawy RA. The Evaluation of Pharmacy Strategic Plan in Past 2013-2016 and Forecasting of New Vision 2030 at the Ministry of Health in Saudi Arabia. J Pharm Pract Community Med. 2018:4(2):93- 101.

24. American Society of Health-System Pharmacists. ASHP statement on the pharmacist's role in antimicrobial stewardship and infection prevention and control. Am J Heal Pharm. 2010;67(7):575-7.

25. Ayliffe GAJ. Infection control in the United Kingdom. Chemotherapy. 1988;34(6):536-40.

26. Cook E, Marchaim D, Kaye KS. Building a Successful Infection Prevention Program: Key Components, Processes and Economics. Infectious Disease Clinics of North America. 2011;25(1):1-19.

27. Moi LL, Tai YC, Wing HS. Infection Control for the Asian healthcare Worker $3^{\text {rd }}$ edition. 2011;153. Available from http://apsic-apac.org/wp-content/ uploads/2016/09/A-Handbook-of-Infection-Control-for-the-Asian-HealthcareWorker.pdf

28. Ontario Agency for Health Protection and Promotion, Provincial Infectious Diseases Advisory Committee. Best Practices for Infection Prevention and Control Programs in All Health Care Settings. Public Health Ontario. 2012;87.

29. Croteau D, Bock C, Hamilton R, Cohen D, Wilkinson D, Jacobson A, et al. Infection control for regulatory professional, Pharmacists ' Edition. 2013.

30. McDonough R. Writing a Business Plan for a New Pharmacy Service. The Dynamics of Pharmaceutical Care: Enriching Patients' Health. 2010;23.

31. Harris IM, Baker E, Berry TM, Halloran MA, Lindauer K, Ragucci KR, et al. Developing a Business-Practice Model for Pharmacy Services in Ambulatory Settings. Pharmacotherapy. 2008;28(2):7e-34e.

32. Sachdev G. Sustainable business models: Systematic approach toward successful ambulatory care pharmacy practice. Am J Heal Pharm 2014;71(16):1366-74

33. PMBOK Guide. A Guide to the Project Management Body of Knowledge. Sixth Edit. Project Management Institute, Inc. 2017.

34. Kaplan RS, Norton DP. The balanced scorecard: Measures That drive performance Harvard Business Review. 2005;83(7):172. [cited 2020 Mar 15]. Available from: https://hbr.org/1992/01/the-balanced-scorecard-measures-thatdrive-performance-2

35. Ray S. The Risk Management Process in Project Management. Project Manager 2017. ProjectManager.com [cited 2020 Mar 15]. Available from: https://www. projectmanager.com/blog/risk-management-process-steps

36. Kaplan RS, Mikes A. Managing Risks: A New Framework. Harvard Business Review. 2012:90(6):48-60. [cited 2020 Mar 15]. Available from: https://hbr. org/2012/06/managing-risks-a-new-framework 